Martina Klost, Stephan Drusch

\title{
Functionalisation of pea protein by tryptic hydrolysis - Characterisation of interfacial and functional properties
}

Journal article | Accepted manuscript (Postprint)

This version is available at https://doi.org/10.14279/depositonce-9553

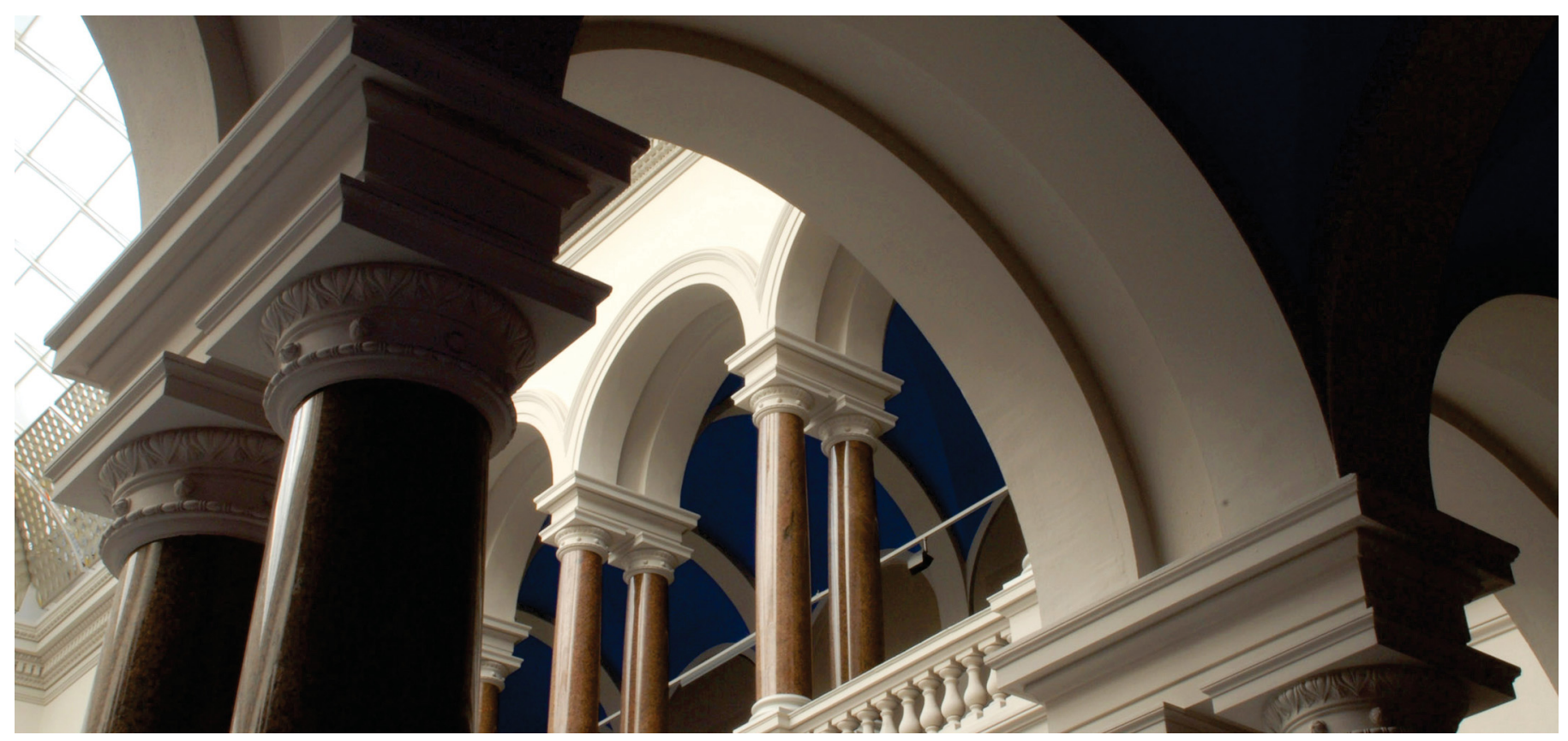

Klost, M., \& Drusch, S. (2018). Functionalisation of pea protein by tryptic hydrolysis - Characterisation of interfacial and functional properties. Food Hydrocolloids, 86, 134-140.

https://doi.org/10.1016/j.foodhyd.2018.03.013 


\title{
Functionalisation of pea protein by tryptic hydrolysis - characterisation of interfacial and functional properties
}

\author{
M. Klost ${ }^{\mathrm{a}^{*}}$ and S. Drusch ${ }^{\mathrm{a}}$ \\ ${ }^{a}$ Technische Universität Berlin, Department of Food Technology and Food Material Science, Königin- \\ Luise-Str. 22, 14195 Berlin, Germany \\ ${ }^{*}$ Corresponding author: martina.klost@tu-berlin.de
}

\begin{abstract}
$\underline{\text { Abstract }}$
With regard to applications in dispersed systems (i.e. emulsions), improving the poor solubility of pea protein in the $\mathrm{pH}$-range applicable to foods $(\mathrm{pH} 3$ to $\mathrm{pH} 7)$ is a prerequisite. To achieve this, a pea protein concentrate was produced on a lab scale using alkaline extraction and subsequent enzymatic hydrolysis to degrees of 2 and $4 \%$. Solubility was improved and interfacial properties were influenced. All samples led to the formation of emulsions but displayed a tendency towards wider oil-droplet size distributions at $\mathrm{pH}$ close to the isoelectric point. Using microscopy, this increase could be attributed to the formation of aggregates, which in turn can be ascribed to lack of repulsion caused by the low absolute values of $\zeta$ potentials. The same lack of repulsion led to stronger and more elastic interfacial films at $\mathrm{pH} 4$ and 5 than at $\mathrm{pH}$ 7. Moreover, film strength increased significantly with increasing degree of hydrolysis. Dilatational experiments imply that hydrolysis enhances in-plane structural rearrangements. Thus, it is concluded that tryptic hydrolysis has the potential to improve the overall stability of emulsions.
\end{abstract}

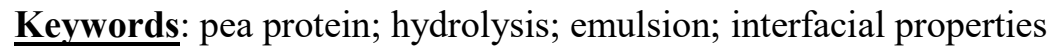

\section{Introduction}

Emulsions generally are thermodynamically and kinetically unstable systems (McClements, 2016). Gravimetrical separation, as in creaming or sedimentation and droplet aggregation, are the most common mechanisms of emulsion instability and often occur in combination (McClements, 2007). Aggregation can be divided into flocculation and coalescence. In flocculation individual oil-droplets form aggregates, without merging with each other, while coalescence describes the fusion of two adjoining oil-droplets (McClements, 2016). Lack of repulsion can lead to aggregation, and the resultant increase in particle-size can thus support creaming (Fennema, et al., 2017). Additionally, the close proximity of oil-droplets in flocculated and/or creamed emulsions may in turn enhance the tendency to coalesce (McClements, 2007). Therefore, in order to prevent destabilisation of emulsions by creaming and flocculation, electrostatic and steric interactions need to be mainly repulsive (McClements, 2004). Furthermore, the ability of interfacial membranes to resist deformation is a key countermeasure to coalescence. One means to promote low deformability are oil-droplet sizes $<1 \mu \mathrm{m}$ (Robins, Watson, \& Wilde, 2002). Another means is to attain highly elastic interfacial films, which should be composed of molecules that show low tendencies to detach from or to be compressed at the interface (Yarranton, Sztukowski, \& Urrutia, 2007), making them able to counteract a decrease of the surface to volume ratio during potential oil-droplet fusion.

In order to be able to incorporate proteins in dispersed food systems, the protein needs to be able to dissolve in the continuous phase. Plant-derived proteins in general and pea protein specifically display low solubilities at $\mathrm{pH}$-values relevant to food systems. Pea protein consists mainly of globular proteins (approx. 60\% (Gueguen \& Barbot, 1988)) that can be divided into legumin, vicilin and convicilin fractions. The first is a hexameric $11 \mathrm{~S}$ fraction $(\sim 360 \mathrm{kDa})$, consisting of six subunits $(\sim 60 \mathrm{kDa})$, each a combination of an acidic $\alpha$-chain $(40 \mathrm{kDa})$ and a basic $\beta$-chain $(20 \mathrm{kDa})$ (R. R. D. Croy, Derbyshire, Krishna, \& Boulter, 1979; Ronald R D Croy, Gatehouse, Evans, \& Boulter, 1980a). The second is a trimeric $7 \mathrm{~S}$ fraction $(\sim 180 \mathrm{kDa})$, consisting of three subunits $(\sim 50 \mathrm{kDa})$ (Gatehouse, Croy, Morton, 
Tyler, \& Boulter, 1981), and the third a tetrameric fraction ( $290 \pm 40 \mathrm{kDa})$ consisting of four subunits ( $\sim 1 \mathrm{KDa}$ ) (Ronald R D Croy, Gatehouse, Tyler, \& Boulter, 1980b). One possible approach to improve protein solubility is controlled enzymatic hydrolysis (Barać et al., 2011; Soral-Smietana, Swigon, Amarowicz, \& Sijtsama, 1998). As the change in peptide profile and size cannot only increase solubility, but can also influence other functional properties (Barać et al., 2011; F. Tamm, Herbst, Brodkorb, \& Drusch, 2016), hydrolysis may be used to tailor functionalities such as interfacial properties, which in turn can influence the emulsifying behaviour (Avramenko, Low, \& Nickerson, 2013; Henning, Mothes, Dudek, \& Schwenke, 1997; Krause \& Schwenke, 1995). Close attention has to be paid to the enzyme selection, the hydrolysis parameters, and the degree of hydrolysis applied since functional properties can also be impaired under certain conditions (Avramenko et al., 2013; Barać et al., 2011; Tsumura et al., 2005). For studies on faba-bean (Henning et al., 1997; Krause \& Schwenke, 1995) and soy-proteins (Ochiai, Kamata, \& Shibasaki, 1982), an improvement in emulsifying properties was connected to the emergence of legumin-T. As for emulsifying properties of pea protein hydrolysates, only little research is available. Barac et al., (2012) used papain and a commercial protease, in combination with different pea genotypes, and found an overall tendency toward improved emulsifying properties after hydrolysis. Humiski \& Aluko, (2007) compared the effect of different enzymes on the emulsifying properties of pea protein hydrolysates and identified the smallest oil-droplet size when using trypsin. Tamm, et al. (2016) reported that oil-droplet size decreased for emulsions stabilised with tryptic hydrolysates of a commercial pea protein but increased for alcalase hydrolysates. So far, only Tamm, et al. (2016) looked into the interfacial properties of pea protein hydrolysates and described an increase in the elastic proportions up to DH 4. However, these authors only chose parameters away from both the IEP and the $\mathrm{pH}$ range relevant to food applications.

The current study therefore aims to estimate the suitability of trypsin hydrolysis of pea protein for emulsion stabilisation in the context of molecular structure and interactions at a $\mathrm{pH}$ region relevant to food applications. It is expected that enzymatic hydrolysis will improve the solubility of pea protein, will positively influence interfacial properties of the protein, and will consequently lead to an increase in emulsion stability without affecting the oil-droplet size.

\section{Materials}

\subsection{Materials}

Dried peas were supplied by Emsland-Stärke GmbH (Emlichheim, Germany), Cremer Oleo (Hamburg, Germany) provided MCT-oil. All materials and chemicals for SDS page were purchased from BioRad Laboratiories GmbH (München, Germany) and all other lab chemicals were purchased from Carl Roth $\mathrm{GmbH}+\mathrm{Co} . \mathrm{KG}$ (Karlsruhe, Germany), Merck and Sigma Aldrich (both Life Science bei Merck, Darmstadt, Germany) and of analytical grade.

\subsection{Methods}

Unless stated differently, all further experiments were carried out as a single determination for the pea protein concentrate (PPC) as well as for each pea protein hydrolysate (PPH), leading to a determination in duplicate for $\mathrm{DH} 2$ and $\mathrm{DH} 4$, respectively.

\subsection{Pea protein concentrate (PPC) preparation and hydrolysis}

PPC was produced on lab scale: dry peas were ground and the flour then dispersed in $0.0375 \mathrm{M} \mathrm{NaOH}$. After $2.5 \mathrm{~h}$ of extraction at room temperature, the sample was centrifuged $\left(5000 \mathrm{~g}, 20^{\circ} \mathrm{C}\right.$ for 30 minutes $)$ followed by lyophilisation of the supernatant. Enzymatic hydrolysis was conducted as described by Tamm, et al. (2015) with modifications. In brief, PPC was dissolved in distilled water and the $\mathrm{pH}$ value adjusted $(0.1 \mathrm{M} \mathrm{HCl} / 1 \mathrm{M} \mathrm{HCl})$. Tryptic hydrolysis (Trypsin from bovine pancreas, Sigma (cat\#T8003, EC:3.4.21.4, 10000 BAEE units/mg Protein)) was conducted at $\mathrm{pH} 8$ and $45^{\circ} \mathrm{C}$ using the $\mathrm{pH}$-stat

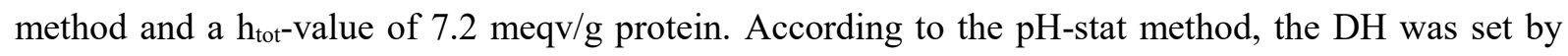


calculation and use of the amount of $\mathrm{NaOH}$ required to achieve the desired $\mathrm{DH}$. The enzyme to substrate ratio was 1:1620 for DH 2 and 1:810 for DH 4. Hydrolysis was stopped by heating samples at $75{ }^{\circ} \mathrm{C}$ for 30 minutes, cooling on ice to room temperature (approx. 20 minutes), and then lyophilizing. Pea protein hydrolysates (PPH) were attained at degrees of hydrolysis of 2 and 4\% (DH 2 and DH 4); PPC may occasionally be referred to as DH 0 . Hydrolysis was carried out in duplicate for each degree of hydrolysis.

\subsection{Solubility}

$50 \mathrm{~g}$ of a solution containing $5 \%$ protein were prepared in distilled water and the $\mathrm{pH}$-value was subsequently adjusted to $\mathrm{pH} 8,7,6,5,4$ and 3 using $0.1 \mathrm{M} / 1 \mathrm{M} \mathrm{HCl}$. Two aliquots of $2 \mathrm{ml}$ were taken at each $\mathrm{pH}$, one of which was measured directly, while the other one was first centrifuged at $13000 \mathrm{~g}$ for 15 minutes before determining the protein content in the supernatant (Method according to Dumas (Dumatherm N64+, Gerhardt, Königswinter, Germany), protein conversion factor 6.25). Solubility was calculated as percentage retained after centrifugation.

\subsection{Molecular weight distribution}

SDS-PAGE was carried out on $4-15 \%$ Criterion ${ }^{\mathrm{TM}}$ TGX ${ }^{\mathrm{TM}}$ Precast Midi Protein Gel according to the BioRad Bulletin 4110001. $10 \mu 1$ of sample (0.1\%in sample-buffer, non reducing conditions (Biorad 2xLaemmli Sample, Cat\# 161-0737)) were applied to the gel alongside lanes of the molecular weight marker $\left(5 \mu 1\right.$, Thermo Fisher PageRuler ${ }^{\mathrm{TM}}$ Prestained Protein Ladder, 10 to $180 \mathrm{kDa}$, Cat\# 26616). Running buffer was Biorad 10xTris/Glycine/SDS Cat\# 161-0732. Photographs of the gel were then transformed to peaks using an image processing program (image J). The molecular weights of the individual bands were calculated using a calibration slope obtained via standardised measurements of the marker bands and matched to individual protein-fractions based on values given in literature. Size exclusion chromatography (SEC) was performed at room temperature (HPLC ÄKTAbasicTM 10 system, Amersham Biosciences, Uppsala, Sweden) with samples of $1 \%$ protein in $0.1 \mathrm{M}$ phosphate buffer. Samples were filtered and passed over a Superdex 200 Increase 10/300 GL (GE healthcare $\mathrm{GmbH}$, Solingen, Germany) column using 0.1 M phosphate buffer as the eluent and an UV detector at $280 \mathrm{~nm}$ for detection. Evaluation took place via a set of standards ((GE healthcare $\mathrm{GmbH}$, Solingen, Germany): feritin (440 kDa), aldolase (158 kDa), conalbumin (75 kDa), ovalbumin (44 kDA), carbonic anhydrase $(29 \mathrm{kDa})$, ribonuclease $(13.7 \mathrm{kDa})$, aprotinin $(6.5 \mathrm{kDa}))$ and the calculation of molecular weights based on the calibration-substances. Both methods were carried out once for the concentrate and once for each degree of hydrolysis at selected $\mathrm{pH}$-values.

\subsection{G-potential}

For the determination of the $\zeta$-potential, solutions of $0.3 \%$ protein were prepared in distilled water, the $\mathrm{pH}$ was adjusted to $\mathrm{pH} 3,4,5,6$ and $7(0.1 \mathrm{HCl} / 1 \mathrm{M} \mathrm{HCl})$, and the $\zeta$-potential was measured in triplicate (Zetasizer Nano-ZS, Malvern Instruments GmbH, Germany).

\subsection{Emulsifying properties}

For emulsifying experiments, $300 \mathrm{~g}$ of protein solutions were prepared in distilled water. The protein content was calculated under consideration of solubility results, aiming at contents of soluble protein $>$ $1.05 \%$. The $\mathrm{pH}$ was adjusted to 3, 4, 5, 6 and $7(0.1 \mathrm{HCl} / 1 \mathrm{M} \mathrm{HCl})$ followed by centrifugation $(10000 \mathrm{~g}$, 20 min., $20^{\circ} \mathrm{C}$ ), determination of the protein content and dilution of the supernatant to $1.05 \%$ protein. Pre-emulsification was carried out in a mixture of $10 \mathrm{~g}$ purified MCT-oil and $190 \mathrm{~g}$ protein-solution at $21500 \mathrm{rpm}$ for $90 \mathrm{~s}$ using an Ultra-Turrax (T25 basic, IKA, Germany) followed by high pressure homogenisation (Panda Plus, Niro Soavi, Germany) at 300 bar and 3 passes. Within five minutes of emulsifying the oil-droplet size distribution (D10, D50, D90 and Span) of the emulsion was measured (Horiba, Retsch Technology GmbH, Haan, Germany). For further examination, microscopic pictures of the emulsions were taken. 


\subsection{Interfacial properties}

All experiments were carried out with $0.25 \%$ protein solutions from the supernatants of the centrifugation step at $\mathrm{pH} \mathrm{4,5}$ and 7 (adjusted with $0.1 \mathrm{HCl} / 1 \mathrm{M} \mathrm{HCl}$ ) at the MCT-oil-water interface. Oscillatory shear-measurements were performed using a rheometer (Physica MCR 301 / 102, Anton Paar GmbH, Ostfildern, Germany) equipped with a biconical disk geometry. Formation of an interfacial film was monitored over $12 \mathrm{~h}$ at $20^{\circ} \mathrm{C}$ (deformation $0.1 \%$, frequency $1 \mathrm{~Hz}$ ). For evaluation, the dynamic complex interfacial shear modulus $\left|\mathrm{G}^{*}\right|$ was calculated using the Rheoplus software. Oscillatory dilatational measurements were performed using a pendant drop tensiometer (OCA 20 Dataphysics $\mathrm{GmbH}$, Germany) with an oscillation drop generator (ODG20, Dataphysics). After interfacial aging of 30 minutes, a frequency sweep was performed $(\triangle \mathrm{A} / \mathrm{A}=3 \%, \mathrm{f}=0.01 \mathrm{~Hz}-1 \mathrm{~Hz})$. From this sweep at the lowest frequency the complex dilatational modulus $\left|\mathrm{E}^{*}\right|$ was calculated by the SCA 20 software.

\section{Results and Discussion}

\subsection{Characterisation of tryptic digestion}

All fractions at DH 0 showed typical patterns in SDS-PAGE (Figure 1a) and SEC (Figure 1b) chromatograms. In the SDS-PAGE profile, beside a wide range of peaks at lower molecular weights, the main storage proteins legumin ( $\sim 60 \mathrm{kDa})$ (Ronald R D Croy, Gatehouse, Evans, et al., 1980a), convicilin ( $\sim 70 \mathrm{kDa})$ (Ronald R D Croy, Gatehouse, Tyler, \& Boulter, 1980b) and vicilin ( $\sim 50 \mathrm{kDa})$ (Gatehouse, Croy, Morton, Tyler, \& Boulter, 1981) could be seen in their monomeric forms. SEC showed the typical quaternary conformation of those proteins: hexameric ( $\sim 380 \mathrm{kDa}$ (Danielsson, 1949 $(331 \mathrm{kDa})($ R. R. D. Croy, Derbyshire, Krishna, \& Boulter, 1979 (390kDa)) for legumin and trimeric ( $\sim 160 \mathrm{kDa}$ (Danielsson, 1949 (186 kDa)) for vicilin.

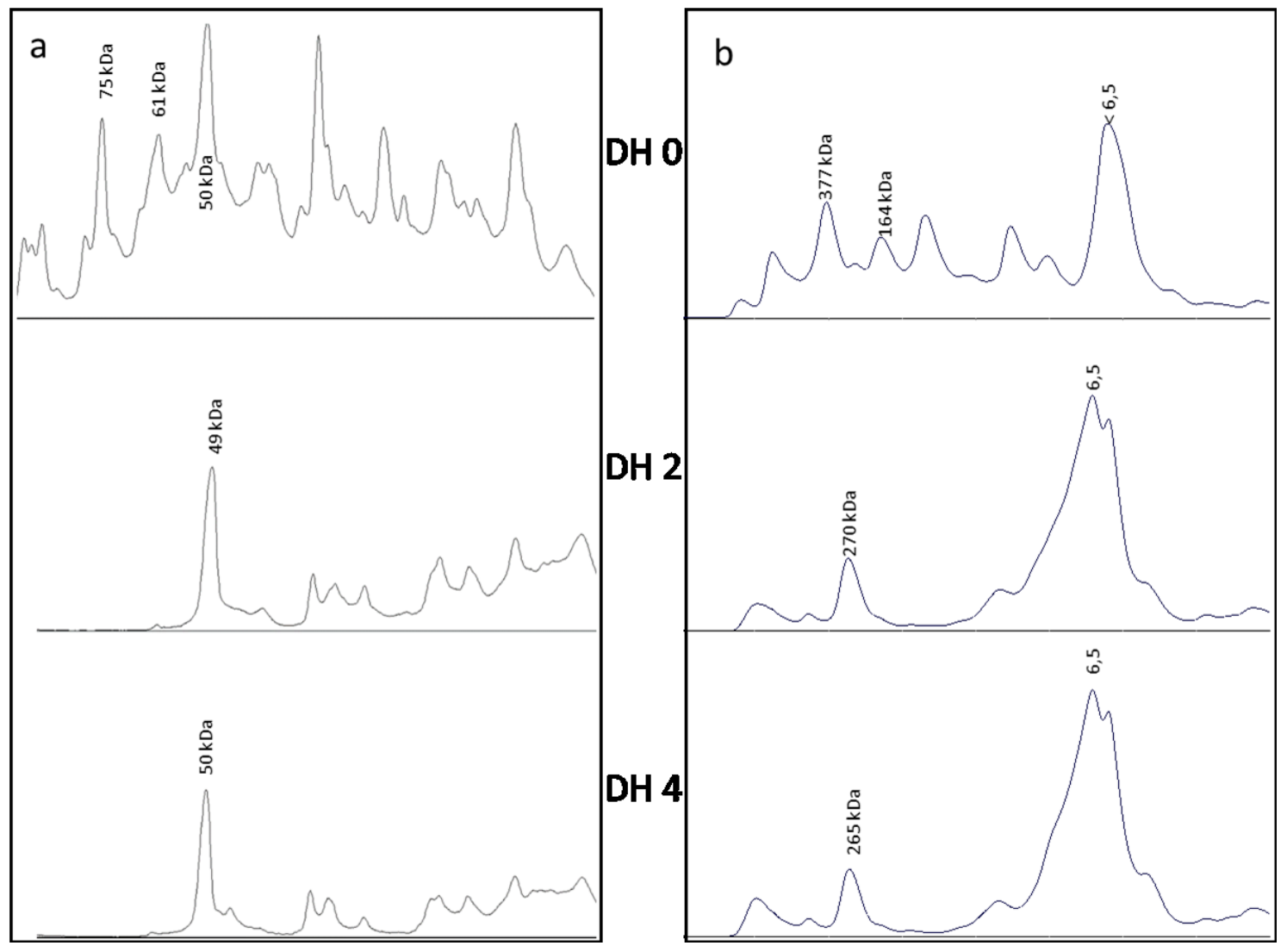

Fig 1: molecular weight distribution of PPC and PPH DH2 and DH 4 as shown in a) SDS-page and b) SEC-chromatography

Convicilin could not clearly be identified in SEC. The fractions of smaller molecular weights observed in both the SDS-PAGE and SEC profiles cannot as easily be matched to specific protein fractions, they 
are likely to be the different vicilin fractions (Gatehouse et al., 1981) as well as of pea albumin and trypsin inhibitors (Ma, Boye, \& Hu, 2017). After hydrolysis, DH2 and DH4 led to similar molecular weight patterns: convicilin, legumin and vicilin were no longer detectable in the SDS-PAGE profile. Instead a variety of smaller peptides as well as one prominent peak at $\sim 47 \mathrm{kDa}$ appeared. In SEC, one peak remained at $\sim 265 \mathrm{kDa}$, whereas all other structures were reduced to significantly smaller peptides. Gatehouse, Lycett, Delauney, \& Croy, (1983) described the first enzymatic attacks on vicilin as usually occurring at two potential sides, which display a high density of polar amino acids and are therefore likely to be located at the molecule's surface. As can be seen from SEC, the quaternary structure of vicilin was lost with hydrolysis. As the convicilin peak (SDS-PAGE) fully disappeared, it is concluded that convicilin was fully digested to small peptides. Tryptic attack on pea legumin starts at the Cterminus of the $\alpha$-chain, (Braudo, et al. 2006) and thus exposes the hydrophobic $\beta$-chain and generates a variety of small peptides carrying a high density of charged side chains. It is also known that with limited hydrolysis legumin- $T$, a very ordered structure $(M=200 \pm 50 \mathrm{kDa}$ (Plumb, Carr, Newby, \& Lambert, 1989)) with a nearly intact tertiary structure and improved techno-functional properties (Krause \& Schwenke, 1995; Ochiai et al. 1982) remains. The improvement in functionality is attributed to the more flexible structure of the $\alpha$-chain and the increased availability of hydrophobic patches from the $\beta$-chain combined with the otherwise nearly intact structure (Schwenke, 2001). The appearance of peaks at $\sim 47 \mathrm{kDa}$ (SDS-Page) and $\sim 265 \mathrm{kDa}$ (SEC) after hydrolysis leads to the conclusion that in this study legumin-T was produced.

\subsection{Solubility, electrostatic properties and emulsification}

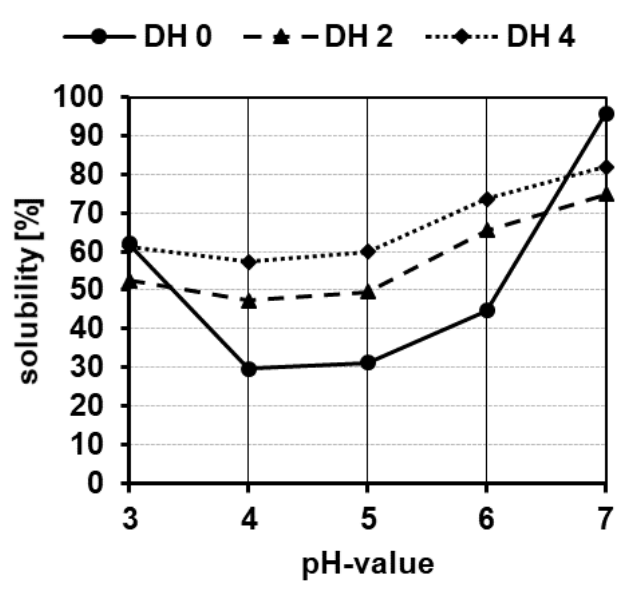

Fig 2: solubility profiles of pea protein concentrate and corresponding hydrolysates in dependence of $\mathrm{pH}$-value

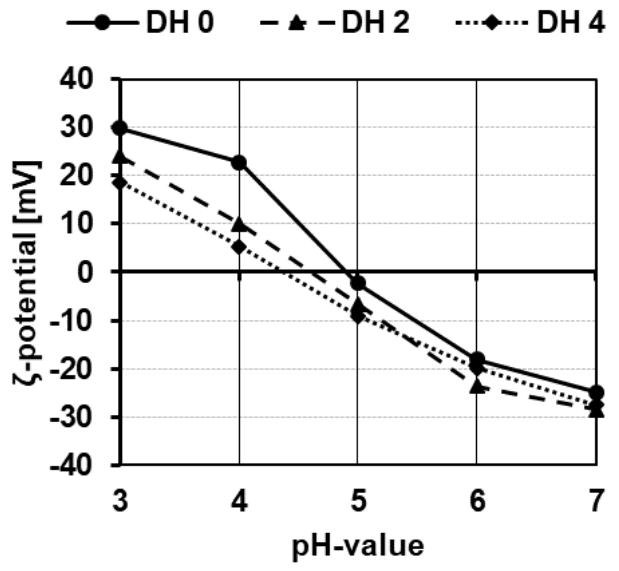

Fig 3: $\zeta$-potential profiles of pea protein concentrate and corresponding hydrolysates in dependence of $\mathrm{pH}$-value

Hydrolysis led to a significant increase in solubility from $30 \%$ (DH 0 ) to approximately $60 \%$ (DH 4 , $\mathrm{pH} 5$ ) at $\mathrm{pH} 4$ to 6 (Figure 2). This was caused by the increased amount of terminal carboxyl- and aminogroups (Panyam, 1996) with these results supported by the findings of Soral-Smietana, et al. (1998). An impaired solubility at $\mathrm{pH} 3$ and 7 for the hydrolysed samples is in accordance with the findings of Barac et al. (2011); Tsoukala, Papalamprou, Makri, Doxastakis, \& Braudo, (2006) and Tsumura et al. (2005). All authors relate this to the increased exposure of interior hydrophobic residues, which can cause aggregation, insolubility and sedimentation of individual peptide fractions. The small peptides from hydrolysis of legumin are likely to aggregate and therefore to be responsible for the decrease in solubility and seem to have had an impact on the electrostatic properties of the hydrolysates (Figure 3) as well. With increasing degree of hydrolysis, a shift in $\zeta$-potential could be observed (Figure 3), moving the IEP from pH 4.91 (DH 0) to $\mathrm{pH} 4.60$ (DH 2) and pH 4.37 (DH 4), respectively. Ochiai, et al. (1982) described a similar effect when investigating tryptic hydrolysis of soybean proteins. In the present study it is concluded, that the fractions involved in the aggregation and decrease of solubility at $\mathrm{pH}$-values 
away from the isoelectric point must consist of more basic than acidic amino acids. Trypsin hydrolysis was carried out at $\mathrm{pH} 8$ and cleavage occurred at the $\mathrm{C}$-terminus of basic amino acids (Braudo et al. 2006). Therefore, it is likely that small, mainly basic peptides from legumin may be close to their isoelectric points and aggregate. This, in turn, would lead to a larger fraction of acidic amino acids in the soluble peptides. The more acidic amino acids a polypeptide contains, the more protons required to bind to all dissociated carboxyl-groups, thus leading to a decrease in the isoelectric point.

In visual assessment of emulsions, creaming was observed close to the isoelectric point. Figure 4a shows the oil-droplet size distribution of freshly formed emulsions stabilised with PPC and the corresponding absolute values of the $\zeta$-potentials. Where oil-droplet size was bimodal, this is depicted by two stacked boxes above each other representing the D10, D50 and D90 of each peak. It is apparent that low $\zeta$ potentials and therefore low electrostatic repulsion led to wider oil-droplet distributions and bimodality. As all these factors implied a possible formation of aggregates from individual small oil-droplets, microscopic pictures of the emulsions were taken (Figure $4 \mathrm{~b}$ ) for confirmation. Thus, creaming was concluded to be caused by aggregation.
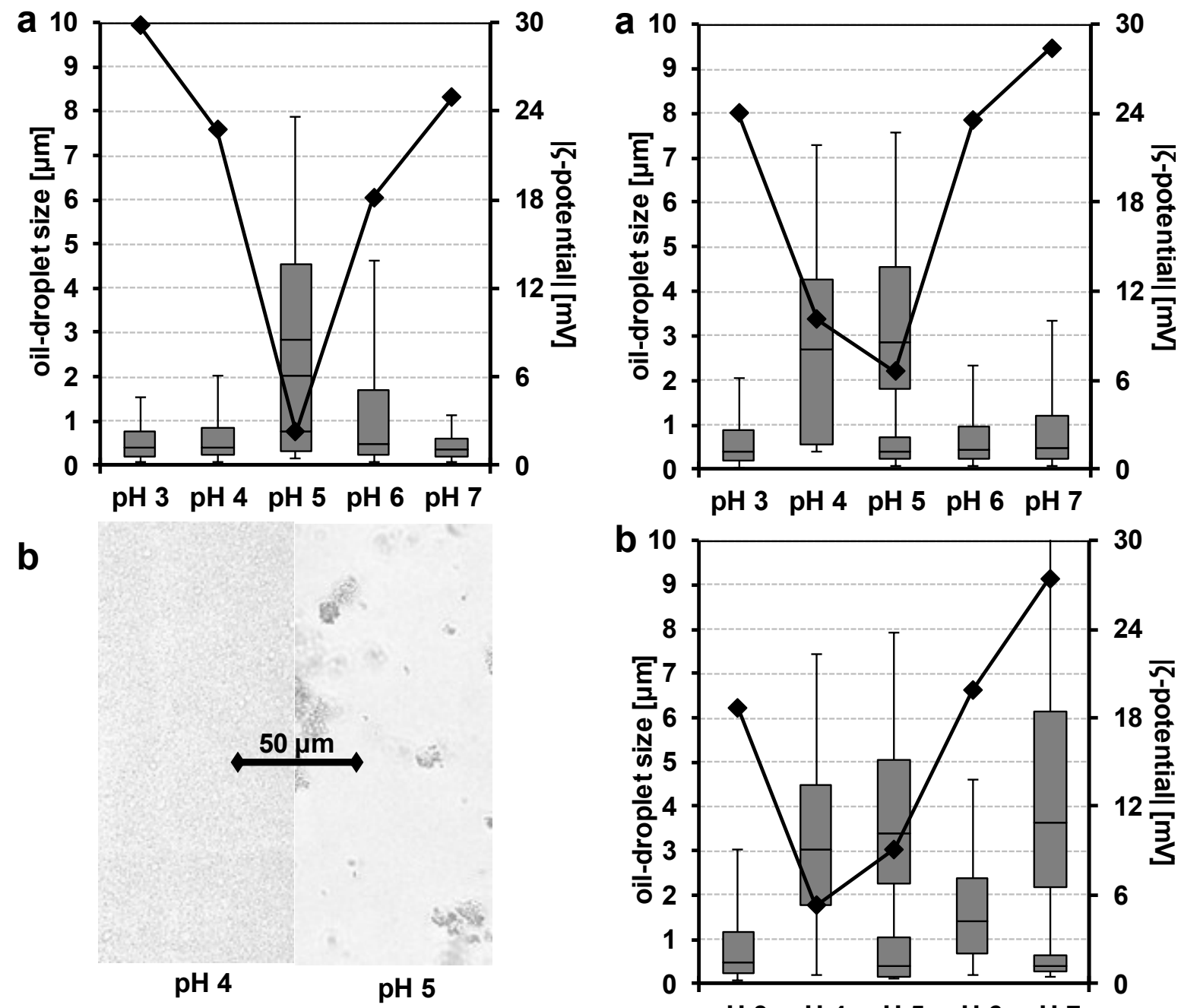

Fig 4: a) oil-droplet size distribution and absolute values of $\zeta$-potential and b) selected microscopic pictures for PPC

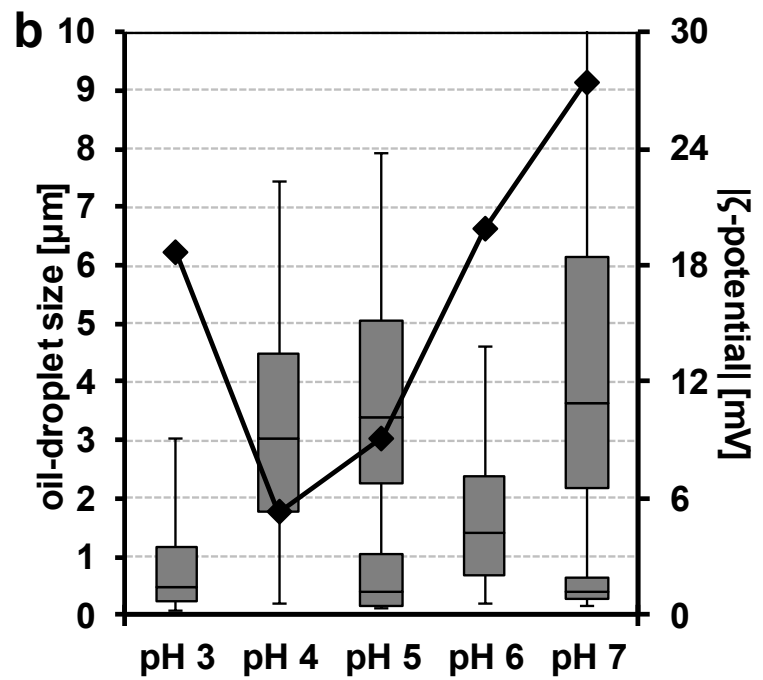

Fig 5: oil-droplet size distribution and absolute values of $\zeta$ potential for a) DH 2 and b) DH 4 
Hydrolysate-stabilised emulsions displayed a similar behaviour at DH 2 (Figure 5a), while at DH 4 an increase in aggregation at $\mathrm{pH} 7$ and an overall increased oil-droplet size was determined (Figure 5b). Where oil-droplet size distributions were wide or bimodal, microscopic pictures again showed aggregation of small, individual oil-droplets rather than an increase in the size of single droplets. While for DH 0 and DH 2, the increase in measured oil-droplet-size and the tendency to aggregate could be attributed to the lack of electrostatic repulsion, whereas, the increased tendency of DH 4 samples to aggregate at $\mathrm{pH} 7$ was most likely due to hydrophobic interactions resulting from increasing amounts of exposed hydrophobic patches with continued hydrolysis. This is in accordance with Henning, et al. (1997) and Krause \& Schwenke, (1995) who also described an initial improvement of emulsifying properties, followed by a decline when hydrolysis was carried out too extensively.

A sufficient resistance to coalescence at all considered $\mathrm{pH}$-values was indicated by the formation of oildroplets $<1 \mu \mathrm{m}$, as deduced from the microscopic pictures in combination with the size of the smaller oil-droplets in bimodal distributions (Robins, et al 2002). As even a few minutes after emulsification, no monomodal distributions could be found, aggregation was presumed to occur almost immediately. However, the initial formation of small oil-droplets at all $\mathrm{pH}$-values pointed to the general ability of the protein and its hydrolysates to rapidly form stable interfacial films.

It can be summarised that lack of electrostatic repulsion played a key role in this study in the formation of flocs. However, the formation of individual oil-droplets with sizes $<1 \mu \mathrm{m}$ implied a low tendency to coalescence. Particularly in flocculated emulsions, the risk of subsequent coalescence is enhanced. Therefore, the interfacial properties of PPC and PPH were examined in order to further estimate the stability of emulsions attained with either sample.

\subsection{Interfacial rheology}

Charge, molecular size and the availability of hydrophobic patches can influence a protein's interfacial properties (Chang, Tu, Ghosh, \& Nickerson, 2015). While lack of electrostatic repulsion leads to aggregation in emulsions and is therefore unwanted, it plays a key role in the formation of interfacial films by enhancing the formation of interactions between individual protein molecules in the interface (i.e. via hydrophobic interactions), in turn leading to stronger interfacial films (Fennema, et al. 2017). The complex interfacial shear modulus $\left|\mathrm{G}^{*}\right|_{12 \mathrm{~h}}$ decreased with increasing $\mathrm{pH}$ and decreasing degree of hydrolysis, indicating stronger intermolecular interactions at lower $\mathrm{pH}$-values and with increasing $\mathrm{DH}$ (Figure 6a). The influence of both $\mathrm{DH}$ and $\mathrm{pH}$ was found to be significant. In the present study, the interfacial dilatational modulus $\left|E^{*}\right|$ (Figure 6b) showed a similar but less pronounced tendency as $\left|G^{*}\right|$, leading to the conclusion that intermolecular interactions were accompanied by additional effects specific to area changes. While the elastic proportions of PPC-films decreased with increasing $\mathrm{pH}$, no significant influence on the loss factor $\tan \delta$ (Figure 6c) of either PPH could be found, implying that despite the lower viscoelasticity of interfacial films at higher $\mathrm{pH}$ values, the ratio between elastic and viscous parts was not affected. These results were in accordance with the findings derived from the slopes of the dilatational frequency sweep (Figure 6d). At slopes $<0.1$, mainly in-plane structural rearrangements (Wan, Yang, \& Sagis, 2016) could be assumed for all hydrolysed samples. As a value of 0.5 would indicate desorption of molecules from the interface and their interchange with the bulk, a mix of in-plane rearrangements and desorption needed to be considered for PPC. 

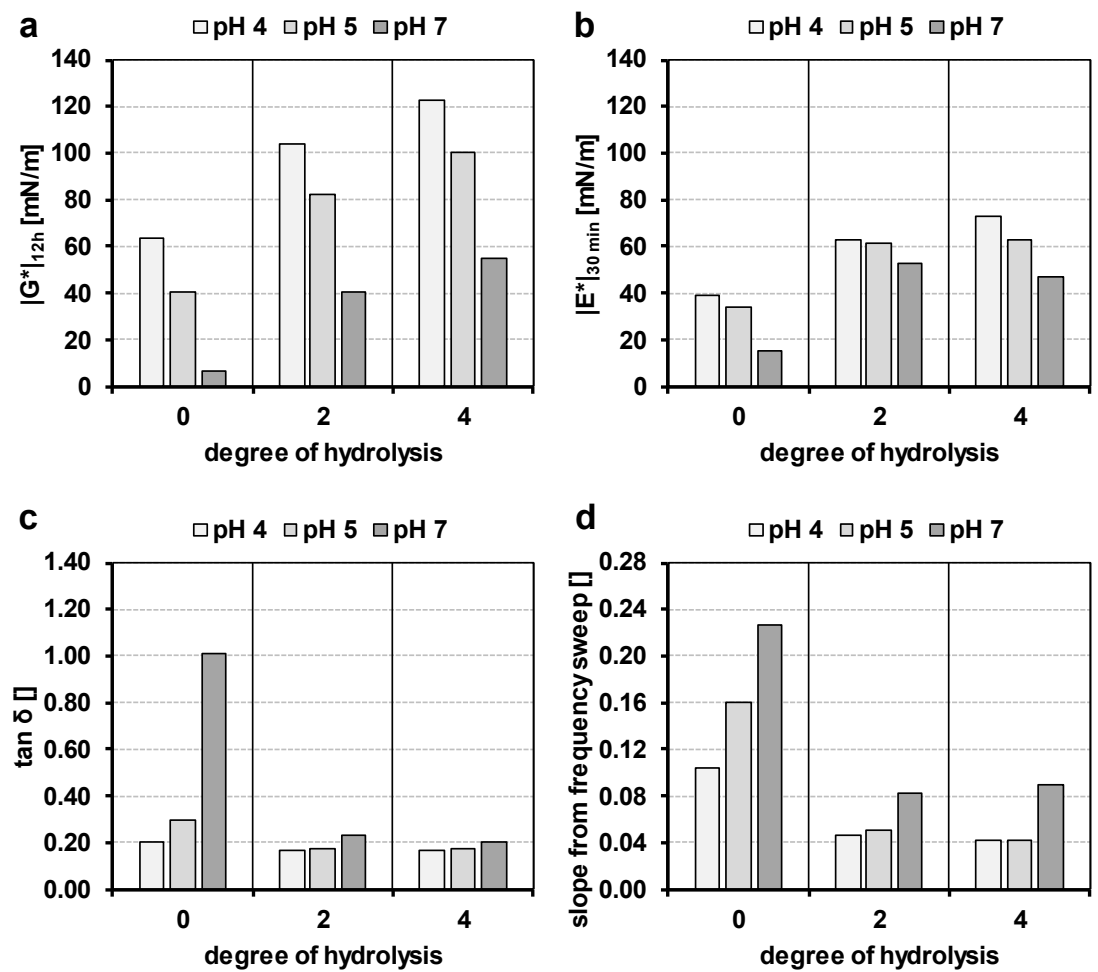

Fig 6: a) $\left|G^{*}\right|_{12 \mathrm{~h}}$, b) $\left.\left.\mathrm{E}^{*}\right|_{30 \min }, \mathrm{c}\right) \mid \tan \delta_{12 \mathrm{~h}}$ and d) slope of the frequency sweeps from dilatational experiments

It was hypothesised, that different interactions must dominate in hydrolysed and unhydrolysed samples, but throughout the considered $\mathrm{pH}$-values, interactions in all hydrolysed samples must be similar in nature. Both, hydrophobic and electrostatic interactions can influence film formation. Assuming an increasing hydrophobicity after hydrolysis (Braudo et al. 2006), especially at $\mathrm{pH} 7$, the ratio between charge and hydrophobicity will shift. In PPC at $\mathrm{pH} 7$, electrostatic repulsion was strong but hydrophobic attraction would have been low, changing to low electrostatic repulsion with low hydrophobicity at $\mathrm{pH} 5$ and higher hydrophobicity and strong electrostatic repulsion at $\mathrm{pH} 4$. Consequently, an overall dominance of electrostatic repulsion with increasing $\mathrm{pH}$ occurred. In contrast, the increased hydrophobicity attained through hydrolysis led to a decline in the influence of the $\mathrm{pH}$ on the balance between electrostatic and hydrophobic interactions, thus interfacial films of the PPHs demonstrated similar viscoelastic behaviour over a wide $\mathrm{pH}$ range.

In summary, interfacial films formed by PPHs, in comparison to PPC, displayed an increase in film strength while maintaining a high proportion of elastic properties independent of $\mathrm{pH}$ Moreover, $\mathrm{PPH}$ are estimated to be less susceptible to protein interchange between interface and bulk.

\section{Conclusions}

The downside of conditions where electrostatic repulsion is low is that creaming, due to aggregation of small individual oil-droplets, is favoured. The upside is that these very same conditions are highly beneficial in improving parameters that indicate stable interfacial films. In this study, samples at DH 2 combined a small oil-droplet size, high elastic proportions of the interfacial film and a low tendency for the desorption of protein molecules from the interface and therefore are likely to resist coalescence. Generally, aggregation in a dispersed system is considered to be detrimental. However, in the past decade, research has started to focus on exploitation of this property by using aggregates for creating turbidity in non-alcoholic beverages, heteroaggregates for simulating creaminess in low calorie foods and encapsulation of bioactives. In this context, tryptic hydrolysates of the present study represent a biomaterial with improved functionality. 


\section{Acknowledgements}

The authors gratefully acknowledge the skill-full experimental work of Marina Eichhorn, Sarah Gleisenberg and Karla Kern.

\section{Funding:}

This work was supported by the "Competence Cluster Nutrition Research" funded by the Federal Ministry of Education and Research, Germany (FKZ: 01EA1408C).

\section{References}

Avramenko, N. A., Low, N. H., \& Nickerson, M. T. (2013). The effects of limited enzymatic hydrolysis on the physicochemical and emulsifying properties of a lentil protein isolate. Food Research International, 51(1), 162-169. https://doi.org/10.1016/j.foodres.2012.11.020

Barać, M., Čabrilo, S., Pešić, M., Stanojević, S., Pavlićević, M., Maćej, O., \& Ristić, N. (2011). Functional Properties of Pea (Pisum sativum, L.) Protein Isolates Modified with Chymosin. International Journal of Molecular Sciences, 12(12), 8372-8387. https://doi.org/10.3390/ijms12128372

Barać, M., Čabrilo, S., Stanojević, S., Pešić, M., Pavlićević, M., Zlatkovic, B., \& Jankovic, M. (2012). Functional properties of protein hydrolysates from pea ( Pisum sativum, L ) seeds. International Journal of Food Science \& Technology, 47(7), 1457-1467. https://doi.org/10.1111/j.13652621.2012.02993.x

Braudo, E. E., Danilenko, A. N., Guslyannikov, P. V., Kozhevnikov, G. O., Artykova, G. P., Lapteva, N. A., ... Duranti, M. (2006). Comparative effects of limited tryptic hydrolysis on physicochemical and structural features of seed $11 \mathrm{~S}$ globulins. International Journal of Biological Macromolecules, 39(4-5), 174-178. https://doi.org/10.1016/j.ijbiomac.2005.12.006

Chang, C., Tu, S., Ghosh, S., \& Nickerson, M. T. (2015). Effect of pH on the inter-relationships between the physicochemical, interfacial and emulsifying properties for pea, soy, lentil and canola protein isolates. Food Research International, 77, 360-367. https://doi.org/10.1016/j.foodres.2015.08.012

Croy, R. R. D., Derbyshire, E., Krishna, T. G., \& Boulter, D. (1979). Legumin of pisum sativum and vicia faba. New Phytologist, 83, 29-35. https://doi.org/10.1111/j.1469-8137.1979.tb00723.x

Croy, R. R. D., Gatehouse, J. A., Evans, I. M., \& Boulter, D. (1980). Characterisation of the storage protein subunits synthesised in vitro by polyribosomes and RNA from developing pea (Pisum sativum L.) - I. Legumin. Planta, 148(1), 49-56. https://doi.org/10.1007/BF00385441

Croy, R. R. D., Gatehouse, J. A., Tyler, M., \& Boulter, D. (1980). The purification and characterization of a third storage protein ( convicilin ) from the seeds of pea ( Pisum sativum L .). Biochemical Journal, 191, 509-516. 
Danielsson, C. E. (1949). Seed globulins of the Gramineae and Leguminosae. The Biochemical Journal, 44(4), 387-400. Retrieved from http://www.pubmedcentral.nih.gov/articlerender.fcgi?artid=1274878\&tool=pmcentrez\&renderty $\mathrm{pe}=\mathrm{abstract}$

Gatehouse, J. A., Croy, R. R. D., Morton, H., Tyler, M., \& Boulter, D. (1981). Characterisation and Subunit Structures of the Vicilin Storage Proteins of Pea (Pisum sativum L.). European Journal of Biochemistry, 118(3), 627-633. https://doi.org/10.1111/j.1432-1033.1981.tb05565.x

Gatehouse, J. A., Lycett, G. W., Delauney, A. J., \& Croy, R. R. D. (1983). Sequence specificity of the post -translational proteolytic cleavage of vicilin, a seed storage protein of pea (Pisum sativum L.). Biochemical Journal, 212, 427-432.

Gueguen, J., \& Barbot, J. (1988). Quantitative and Qualitative Variability of Pea ( Pisum sativum L .) Protein Composition. Journal of the Science of Food and Agriculture, 42, 209-224.

Henning, T., Mothes, R., Dudek, S., \& Schwenke, K. D. (1997). Structural and functional changes of faba bean legumin during super- limited tryptic hydrolysis. Nahrung - Food, 41(2), 81-86.

Humiski, L. M., \& Aluko, R. E. (2007). Physicochemical and bitterness properties of enzymatic pea protein hydrolysates. Journal of Food Science, 72(8). https://doi.org/10.1111/j.17503841.2007.00475.x

Krause, J. -P, \& Schwenke, K. D. (1995). Changes in interfacial properties of legumin from faba beans (Vicia faba I.) by tryptic hydrolysis. Food / Nahrung, 39(5-6), 396-405. https://doi.org/10.1002/food.19950390505

Ma, Z., Boye, J. I., \& Hu, X. (2017). In vitro digestibility, protein composition and techno-functional properties of Saskatchewan grown yellow field peas (Pisum sativum L.) as affected by processing. Food Research International, 92, 64-78. https://doi.org/10.1016/j.foodres.2016.12.012

McClements, D. J. (2004). Protein-stabilized emulsions. Current Opinion in Colloid and Interface Science, 9(5), 305-313. https://doi.org/10.1016/j.cocis.2004.09.003

McClements, D. J. (2007). Critical review of techniques and methodologies for characterization of emulsion stability. Critical Reviews in Food Science and Nutrition, 47(7), 611-649. https://doi.org/10.1080/10408390701289292

Ochiai, K., Kamata, Y., \& Shibasaki, K. (1982). Effect of tryptic digestion on emulsifying properties of soy protein. Agricultural and Biological Chemistry, 46(1), 91-96. https://doi.org/10.1080/00021369.1982.10865031

Panyam, D. (1996). Enhancing the functionality of food proteins by enzymatic modification. Trends in Food Science \& Technology, 7(4), 120-125. https://doi.org/10.1016/0924-2244(96)10012-1

Plumb, G. W., Carr, H. J., Newby, V. K., \& Lambert, N. (1989). A study of the trypsinolysis of pea 11S globulin. Bba, 999, 281-288.

Robins, M. M., Watson, A. D., \& Wilde, P. J. (2002). Emulsions - Creaming and rheology. Current Opinion in Colloid and Interface Science, 7(5-6), 419-425. https://doi.org/10.1016/S13590294(02)00089-4 
Schwenke, K. D. (2001). Reflections about the functional potential of legume proteins: A review. Nahrung - Food, 45(6), 377-381. https://doi.org/10.1002/1521-3803(20011001)45:6<377::AIDFOOD377>3.0.CO;2-G

Soral-Smietana, M., Swigon, A., Amarowicz, R., \& Sijtsama, L. (1998). The solubility of trypsin pea protein hydrolysates (Short communication ). Nahrung - Food, 42(03-04), 217-218.

https://doi.org/10.1002/(SICI)1521-3803(199808)4210.1002/(SICI)15213803(199808)42:03/04<217::AID-FOOD217>3.0.CO;2-2

Tamm, F., Gies, K., Diekmann, S., Serfert, Y., Strunskus, T., Brodkorb, A., \& Drusch, S. (2015). Whey protein hydrolysates reduce autoxidation in microencapsulated long chain polyunsaturated fatty acids. European Journal of Lipid Science and Technology, 1960-1970. https://doi.org/10.1002/ejlt.201400574

Tamm, F., Herbst, S., Brodkorb, A., \& Drusch, S. (2016). Functional properties of pea protein hydrolysates in emulsions and spray-dried microcapsules. Food Hydrocolloids, 58, 204-214. https://doi.org/10.1016/j.foodhyd.2016.02.032

Tsoukala, A., Papalamprou, E., Makri, E., Doxastakis, G., \& Braudo, E. E. (2006). Adsorption at the air-water interface and emulsification properties of grain legume protein derivatives from pea and broad bean. Colloids and Surfaces B: Biointerfaces, 53(2), 203-208. https://doi.org/10.1016/j.colsurfb.2006.08.019

Tsumura, K., Saito, T., Tsuge, K., Ashida, H., Kugimiya, W., \& Inouye, K. (2005). Functional properties of soy protein hydrolysates obtained by selective proteolysis. LWT - Food Science and Technology, 38(3), 255-261. https://doi.org/10.1016/j.lwt.2004.06.007

Wan, Z., Yang, X., \& Sagis, L. M. C. (2016). Nonlinear Surface Dilatational Rheology and Foaming Behavior of Protein and Protein Fibrillar Aggregates in the Presence of Natural Surfactant. Langmuir, 32(15), 3679-3690. https://doi.org/10.1021/acs.langmuir.6b00446

Yarranton, H. W., Sztukowski, D. M., \& Urrutia, P. (2007). Effect of interfacial rheology on model emulsion coalescence. I. Interfacial rheology. Journal of Colloid and Interface Science, 310(1), 246-252. https://doi.org/10.1016/j.jcis.2007.01.071 